\section{Breaking the Game: the Traversal of the Emergent Narrative in Video Games}

\section{ABSTRACT}

In video games the player's actions shape the narrative of their personal experience, molding what otherwise would be a linear course. This emergent narrative is in a state of constant transformation, dependent on how the player influences it.

This paper explores how the players traverse ergodic media such as video games and how narrative emerges from the interactions between them and the system. In a previous text we have proposed three types of traversal in video games (Cardoso \& Carvalhais, 2013): 1) that in which the player has the ability to choose between mutually exclusive paths; 2) that in which the player has the ability to expand the narrative; and 3) that in which the traversal is determined by the disposition of the other actors in the game world towards the player and each other.

This paper intends to further contribute by adding another one: 4) a type of traversal that is rooted in the exploitation of any flaws and glitches in the system, allowing the player to traverse the game through an overlooked side of the algorithm, journeying through a world of unpredictable behaviours and events, that may ultimately break the game altogether.

Keywords: Agency; Ergodic Media; Glitch; Narrative; Video Games

\section{Pedro Cardoso \\ ID+, Faculdade de Belas Artes, Universidade do Porto | Portugal \\ -.-- \\ pcardoso@fba.up.pt}

\section{Miguel Carvalhais}

ID+, Faculdade de Belas Artes, Universidade

do Porto | Portugal

miguel@carvalhais.org

\section{1 | INTRODUCTION}

In video games, narrative emerges from a dialectic relationship between the player and the system, a relationship that makes the game progress. The players' actions determine the course of events and thus the course of their personal experience.

Choice is at the core of video games, and by allowing the player to choose, the game progresses. Without the player's input the game is on hold, it becomes pure process, as stated by Alexander Galloway when describing the 'ambience act' (2006). The game system requires the player to act in order to develop, and to progress the narrative, no matter to what end.

Video games require the player to develop a nontrivial effort when engaging with them (Aarseth, 1997). Their actions determine their own personal experience, or traversal, that may be defined as the experience of travelling across something. In this case we use the term 'traversal' to define how journeying through the game becomes a personal experience. Traversal regards experiencing the narrative that emerges from the interaction between the player and the system (Cardoso \& Carvalhais, 2013). It regards something that is more processintensive (Carvalhais, 2013) and less hardcoded; the 'ludonarrative' (Bissel, 2011), or Marc LeBlanc's 'emergent narrative' (Salen \& Zimmerman, 2004). [1] 
Also, traversal in ergodic media such as video games tends to not be easily re-experienceable (Bissel, 2011), as the conditions that created a specific event or behaviour may not be recreated with exactness. They may somehow be very similar, but still not exactly the same.

These types of traversal define the dynamics of the narrative experience of the game, even determining the replayability of the game itself, and how open, massive and (un)predictable the game world may be. And eventually, how astray the player can go from the game's objectives and purposes, or even from what was initially designed by the developers themselves.

By acknowledging the player's experience, they define the context that game designers and developers will work on in order to produce the algorithms that will govern that same game world. Establishing the rules and boundaries of the paths that allow the player to traverse the game, thus settling how much of the play experience will be determined by hardcoded, scripted events or by procedural, emergent occurrences (Allison, 2010). The types of traversal proposed result from different forms of tension between these.

\section{2 | TYPES OF ERGODIC TRAVERSAL}

In Traversing the Emerging Narrative in Interactive Narratives and Video Games (Cardoso \& Carvalhais, 2013), we have proposed three types of ergodic traversal: branching, bending, and modulating. We will describe each, including a new type: exploiting, that we are now adding.

\subsection{BRANCHING}

Branching happens when the player is asked to choose between mutually exclusive paths, and is at the core of ergodic works as the player is constantly reminded of choices and paths not travelled (Aarseth, 1997, p. 3). Many video games make this very explicit, even forcing the player to make moral choices. In Bioshock (2007) and Infamous (2009) the player has to choose between egotistical and self-centered actions - following a darker side of the narrative - or selfless and sometimes altruistic actions - helping others and thus embodying a sort of paladin or hero. In Bioshock the player has to choose between killing the Little Sisters and collecting ADAM (a valuable item in the game) or helping them. In Infamous the player embodies a character that possesses superpowers, and that has to choose between becoming a super-hero or a villain. Along the game the player has to complete multiple quests, and these challenges may promote one side or the other. Completing quests from one side usually blocks the access to quests from the other.

Silent Hill (1999) has several possible endings, which the players may access depending on the course of events along their traversal. Actually, the multiple endings are so common in video games that players already assume that different endings may exist, even when that may not be true. One of the main playable characters in Final Fantasy VII (1997), Aeris, dies several hours into the game. This constitutes a huge loss for the player, mainly due to the time they have already invested on that character. Aeris's death had such an impact that fans became interested in finding a way for her not to perish. They intensively searched for an alternative course of events, and thus a different ending, although to date we still haven't found a way to prevent her from dying.

Branching is very evident in many video games. Let's think about Super Mario Bros. (1985) although many other games could be used as examples. This game grants the player the ability to choose between alternative paths. In the first level the player may choose to ignore the pipes and keep heading straight to finish line; but the player may decide to go down one of those pipes into a room filled with coins [2] only to go back up through another pipe, emerging in a part of the world closer to the end, but now unable to go back (to the left), to a part of the world that is now inaccessible.

\subsection{BENDING}

Bending occurs when the player is allowed to access different layers of information, increasing her knowledge of the game world. When she is able to explore optional non-mutually exclusive paths (Miller, 2010), lengthening the game (Bogost, 2010) and even experiencing parallel narratives. As games contain more than the player may experience (Bissel, 2011), they may be curious and willing to explore the intricacies and the details of its world. Ian Bogost affirms that this is one of the major differences between cinema and video games: "If 'edit' is the verb that makes cinema what it is, then perhaps videogames ought to focus on the opposite: extension, addition, prolonging." (2010)

Thus, bending usually reveals hidden and/or optional areas, items, behaviours, or actions. Games like The Legend of Zelda: A Link to the Past (1991), Final Fantasy VII (1997), Grand Theft Auto IV (2008), Borderlands (2009), Heavy Rain (2010), The Elder Scrolls V: Skyrim (2011) are just some examples that 
use bending as a method to expand their worlds and allow the player to engage in exploration. In these games the player may not follow the main quest or storyline - which would lead to closure - but may instead wish to explore the open-world that the game offers.

Open-world video games offer the player the choice to engage in an immense range of optional activities that do not necessarily contribute to closure, but rather to expand the player's experience. Actually, the player may spend much more time exploring optional content than on the main storyline or quest - trying to achieve closure.

Heavy Rain is not an open-world game but it allows the player to bend the game as it constantly engages them in side-activities.

Stories are about time passing and narrative progression. Games are about challenge, which frustrates the passing of time and impedes narrative progression. (Bissel, 2011)

It seems interesting to allow the player to bend the game, but undergoing in optional tasks has its shortcomings. If bending doesn't contribute to meaningful and engaging experiences it may become a dull and painful chore for the player to undertake. We may call these fillers, as they are features that do not contribute to the overall experience of the game. Grand Theft Auto: San Andreas (2004) offers one example of this. The playable character may get fat by eating fast food, and become slim when engaging in physical activity. But, none of these features seem to be meaningful when playing the game. Thus, we question ourselves: why are they there in the first place, and why should the player perform them? (Bissel, 2011)

\subsection{MODULATING}

Modulating is possible when the player is able to craft relationships, and to regulate the disposition of characters or actors in the game towards the playable character and/or between themselves. There is a social framework that can be molded as the player acts within the game world. And what may be honorable and righteous to a certain character or actor may be nefarious to another. Fallout 3 (2008) constitutes an excellent example of this, due to the intricate social framework that links the game's characters and actors.

[Fallout 3's Karma system] works so that every action you take to help or hurt others will subsequently affect their disposition and actions toward you. More importantly perhaps, it will also affect the attitude of that character's "social network" and thus the attitude toward you that characters you may not have even seen before will take. In this way, if you affect a character in a positive way, their friends may also have a positive disposition toward you, and be willing to help you later, or if you hurt the character, they might do the same to you. (Games, 2011)

So, depending on the actions taken by the player, many non-playable characters become friend or foe. Actually, the player's actions may reverberate both favourable and dire consequences; they may turn some characters to the player's side and others against him. For example, in the Grand Theft Auto series if the player completes an assignment for some gang, the rival gang (or gangs) may become their enemies, and if she tries to travel through those gangs' territories they may engage the player as an enemy.

The Walking Dead (2012) is another video game whose main feature is to force the player to engage into meaningful social relationships. The storyline puts the player in the role of an inmate that accidentally is set free and forced to survive in a world full of zombies. Occasionally, the player is forced to choose between who lives and dies, and who eats and who has to wait, etc. Most decisions will please some characters and displease others, and the player has to manage the dynamics of that social network, considering that they must survive in a harsh environment.

So, here action actually becomes meaningful through consequence (Games, 2011). It is the consequences that are manifested through this social fabric that give meaning to the player's actions, that mold the narrative, and that make the game progress.

\subsection{EXPLOITING}

Although the previous types of traversal are quite different between themselves, they bear one thing in common: they operate in a part of the system that was planned, that was meant to be, that was designed. As soon as we acknowledged this fact, we started to ponder the possibility of another type of traversal, an alternative way to experience the game. A way that is unbound (or not exclusively bound) to the side of the system that was intentionally designed, but to that side that is dysfunctional, emergent, and untested.

When players traverse a game by exploring glitches and resorting to bugs in the system, we may say that 
they are exp/oiting it. Glitches are manifestations of specific malfunctions within the system; they result from unforeseen and unresolved problems, and are something that was not supposed to be. Some of these glitches may actually prevent the player from progressing - originating frustration and disapproval - and since they were not supposed to exist in the first place, developers tend to eradicate them over time. In fact, contemporary video games often support online updating, allowing developers to patch the system as a means to erase errors in the code and to prevent system malfunctioning.

But glitches may also originate the opposite; they may open a door to a new and unpredictable set of possibilities for the player to experience. For example, in Final Fantasy IV (1991) the player may take advantage of a glitch in the system that will prevent her from entering a town called Mist, the location of key events waiting to take place. If the player skips the town those events never take place and the narrative of the game is broken, at least to a certain point.

At the beginning of Final Fantasy IV, your heroes Cecil the Dark Knight and Kain the Dragoon are sent to deliver a package to the sleepy town of Mist. Once you get there, the package detonates and sets fire to the town. You meet a little girl named Rydia, whose mom you've just killed. She summons a monster to get revenge. Then Cecil blacks out. He wakes up in a field on the other side of the mountains. Kain is gone. Rydia is Iying nearby, unconscious. Cecil picks up the girl and heads out into the desert.

By skipping Mist [Rydia's hometown], we skip that entire sequence. The package never explodes. Rydia's mom never dies. Kain never leaves. And the whole game is broken as a result. (Schreier, 2013)

In the earlier Final Fantasy games the player's abilities to explore the world map increase as the game and its narrative progress. The player usually starts by traveling across the world map on foot, acquiring, later in the game, other means of travel such as ground and water vehicles, or by riding a sort of fictional birds called 'Chocobos'. Traditionally, much later into the game, the player is able to get the means to travel by air - usually through an airship - that gives her the possibility to journey to places that were once unreachable.

Thanks to a glitch, in Final Fantasy VI (1994), the player is able to acquire an airship way too early. This enables the player not only to further explore the game world, but also to experience narrative sequences out of order and witness other strange events.

But there's a hell of a lot you can do when you have the airship this early in the game. You can do story events out of order, break sequences, and glitch out Final Fantasy $\mathrm{VI}$ in all sorts of ways. (Schreier, 2012)

As, at that time, the player was supposed to be constrained to a given location, the events in other parts of the game world could not, in principle, have been triggered. But when the player suddenly appears in parts of the world where she was not supposed to be in, the system assumes (sometimes) that the game that should lie behind was already experienced and tries to keep on developing the narrative, although it could not make a more wrongful assumption. And therefore, the game sometimes breaks.

In Tomb Raider (1996), the player can usually only progress in the game if she finds a given key-item that opens doors or gates that block her path. Finding that item may be the motivation for the player to explore the game world and to undertake the sub-challenges that are eventually encountered. But sometimes the player may manage to go through those blocked doors without using a key. The player just has to execute a couple of moves with her avatar in order to be transported to the next room. By doing so, some enemies may already have been spawned in that specific room, but since the door itself hasn't been opened, they are not active and remain static, inert. This is an interesting glitch that illustrates how the game system was still not aware of the player's presence. It is as if the player has vanished from the game's radar.

Some glitches can be found almost anywhere, but some are bound to specific locations or events. In Tomb Raider 3 (1998), there is a bug in the code that allows the player's avatar to move from the floor straight to the roof. Players normally use this to further explore the game, to reach inaccessible areas, or at least not so easily accessible. In Super Mario Bros. (1985) an unforeseen problem in the code allows the player to jump on a Goomba (a common enemy in Super Mario games) from below. In other words, in a move that will surely kill Mario (the game's playable character), the glitch allows him to not only to survive but also to kill his enemy! Curiously, this glitch was first discovered when a computer program was playing this game.

In The First Level of Super Mario Bros. is Easy with 
Lexicographic Orderings and Time Travel... after that it gets a little tricky (2013) Tom Murphy VII reports the work he underwent in creating a software program - Playfun - that plays Super Mario Bros. (1985). $\mathrm{He}$ also published a video showing the program learning how to play the game. At a given moment, his program finds a way to kill Goombas jumping from below. For a moment, he thought that was an isolated incident, but the program started to use it recurrently as a gameplay method.

Mario bounces off one Goomba up into the feet of another. Not only doesn't he have enough velocity to reach the platform, but he's about to hit that Goomba from below. Believe it or not, this ends well: Playfun is happy to exploit bugs in the game; in this case, that whenever Mario is moving downward (his jump crests just before the Goomba hits him) this counts as "stomping" on an enemy, even if that enemy is above him. The additional bounce from this Goomba also allows him to make it up to the platform, which he wouldn't have otherwise! (Murphy VII, 2013)

This raises the following question: Is this type of traversal cheating? Is a player that is exploiting the game cheating, or not? Was Murphy's computer program cheating? And can computer programs even cheat?

\section{3 | TO CHEAT OR NOT TO CHEAT?}

In the world of video games, cheats usually allow players to subvert the original mode of gameplay, either by easing the game-adding extra lives is just one example-or just to achieve certain locations, events, or obtain goods that they couldn't otherwise get. Cheats usually are hardcoded in the system, and many times they are development too/s that allow programmers to explore the game world when they are working on it. Summarizing, they may start as development tools and when they reach the hands of the players they become cheats. So, we may say that they are intentionally programmed into the game system.

On the other hand, when exploiting the game, the player is pursuing new fields of possibilities previously unseen and unintentionally programmed into the system, thus exploring the game beyond what was previously established and tested. We may even say that the player is aware of the game as a computational system and that she seeks its frailties. So, now the question is: can this be considered cheating?
Lessig has suggested that "code is law," but if code is law it is law as a "management of infractions." (Goffrey, 2008, p 19)

We do not think so. We believe that the player is not cheating the game, but breaking it. We use this term because the game may actually collapse! The system may become unstable and crash, the player may be prevented from progressing in the game, as the sequences of certain events may be shuffled resulting in paradoxes and other abnormal activities, behaviours and events. Depending on the glitches and how they affect the system, the traversal may become rather unpredictable.

So, cheating subverts the ludological system, adding changes to the original rules, to a mode of play, or to the game state. Exploiting the game consists in breaking it, in exploring the limits, the fallibilities and shortcomings of the system that supports the game itself without changing its rules. The glitches were actually there all the time; they are part of the system. But, the major difference is that cheats are intentionally designed, and glitches are accidents. We may say that they are accidental rules of the system.

The algorithm, which Turing understood as an effective process for solving a problem, is merely the set of instructions fed into the machine to solve that problem. Without the algorithm then, there would be no computing. (Goffrey, 2008, p. 16)

\section{4 | CONCLUSIONS AND FUTURE RESEARCH}

This paper pays a contribution by adding one more type of traversal to the previously enunciated (Cardoso \& Carvalhais, 2013), a type that consists in exploiting the game, in taking advantage of the system's frailties, problems and inconsistencies, in order for the player to explore alternative narratives operating in a part of the system that is untested, accidental, and not meant to exist. This fact makes us wonder if there are more types of traversal that still operate in a similar fashion. In other words, it makes us wonder if there is a way of traversal that consists in adding new elements, tampering or even hacking the system, breaking the boundaries of the system itself.

Also, the discussion about whether exploiting the game was or not cheating, raised another question: Can cheating be another type of traversal? If cheating is different from exploiting, can it consist in an alternative way of experiencing the game? And how does that differ from the other types of traversal? 
We find video games to embed multiple types of traversal, but how those types relate in a specific game is still to unravel. Understanding the relationship between these types of traversal seems now even more crucial to future studies on this subject. Grasping the ways they relate with each other can provide us with means to interpret differences between games themselves, to understand the gameplay dynamics they promote, and, ultimately, to unravel new and innovative games, or at least alternative ways of experiencing and thus designing them.

We believe that these types of traversal not only contribute to a definition of the player's personal experience of journey through a given video game, but may also provide insight on the experience of the interactor while using other computational media, in diverse fields of study from interactive media art to user experience and interaction design.

\section{REFERENCES}

Aarseth, Espen. (1997). Cybertext: Perspectives on ergodic literature. Baltimore: The Johns Hopkins University Press.

Allison, Fraser. (2010). The game narrative triangle. Retrieved from Red Kings Dream website: http:// redkingsdream.com/2010/07/the-game-narrativetriangle/

Bethesda Game Studios, 4J Studios. (2006). The Elder Scrolls IV: Oblivion.

Bethesda Game Studios. (2008). Fallout 3.

Bethesda Game Studios. (2011). The Elder Scrolls V: Skyrim.

Bissel, Tom. (2011). Extra lives: Why video games matter.

Bogost, Ian. (2010). Persuasive games: The picnic spoils the rain. Gamasutra: The art \& business of making games. Retrieved from Gamasutra website: http://www.gamasutra.com/view/feature/4412/ persuasive_games_the_picnic_.php?print $=1$

Cardoso, Pedro, \& Carvalhais, Miguel. (2013). Traversing the emerging narrative in interactive narratives and video games. Paper presented at the Avanca | Cinema: International Conference Cinema Art, Technology, Communication, Avanca, Portugal.

Carvalhais, Miguel. (2013). Traversal hermeneutics: The emergence of narrative in ergodic media. Paper presented at the $\times$ CoAx 2013, Bergamo, Italy.
Core Design. (1996). Tomb Raider.

Core Design. (1998). Tomb Raider 3.

Galloway, Alexander R. (2006). Gaming: Essays on algorithmic culture (Vol. 18). Minneapolis: University of Minnesota Press.

Games, Alex. (2011). Fallout 3: How relationshiprelevant decisions craft identities that keep bringing us back to enjoy the horrors of the nuclear wasteland. In Drew Davidson (Ed.), Well played 3.0: Video games, value and meaning: ETC Press.

Gearbox Software. (2009). Borderlands.

Goffrey, Andrew. (2008). Algorithm. In Matthew Fuller (Ed.), Software studies: A lexicon (pp. 15-20). Cambridge, Massachusetts: The MIT Press.

Irrational Games, Digital Extremes. (2007). Bioshock.

Konami Computer Entertainment Tokyo. (1999). Silent Hill.

Miller, Ben. (2010). Immersive game design: Indigo prophecy. Drew Davidson (Ed.), Well played 2.0: Video games, value, and meaning: ETC Press. ISBN: 978-0-557- 84451-7.

Murphy VII, Tom. (2013). The first level of Super Mario Bros. is easy with lexicographic orderings and time travel ... after that it gets a little tricky. Paper presented at the SIGBOVIK 2013.

Nintendo Creative Department. (1985). Super Mario Bros.

Nintendo EAD. (1991 [JP], 1992 [EU, NA]). The Legend of Zelda: A Link to the Past.

Quantic Dream. (2010). Heavy Rain.

Rockstar North. (2004). Grand Theft Auto: San Andreas.

Rockstar North, Rockstar Toronto. (2008). Grand Theft Auto IV.

Salen, Katie, \& Zimmerman, Eric. (2004). Rules of play: Game design fundamentals: MIT - Massachussetts Institute of Technology.

Schreier, Jason. (2012). How to break final fantasy vi. Random Encounters. Retrieved 25/05/2013 
Schreier, Jason. (2013). How to break final fantasy iv. Random Encounters. Retrieved 25/05/2013

Square. (1991). Final Fantasy IV.

Square. (1994). Final Fantasy VI.

Square Product Development Division 1. (1997). Final Fantasy VII.

\section{ENDNOTES}

[1] Marc LeBlanc referred these terms at the 1999 Game Developers Conference.

[2] Coins are collectable items in the game, that if enough are collected the player is rewarded with one extra life, a chance to play again.

\section{BIOGRAPHIC INFORMATION}

Pedro Cardoso is a communication designer, researcher, and a PhD student pursuing studies in video games and new media. He is a guest lecturer at the University of Porto.

www.pedrocardoso.pt.vu

Miguel Carvalhais is a communication designer and a musician. He is a professor of interaction design and new media at the University of Porto.

www.carvalhais.org 